\title{
Blood pressure variability and its association with echocardiographic parameters in hypertensive diabetic patients
}

Daniela Massierer ${ }^{1,3}$, Liana Farias Leiria ${ }^{2,3}$, Mateus Dorneles Severo ${ }^{2}$, Priscila Dos Santos Ledur ${ }^{2}$, Alexandre Dalpiaz Becker ${ }^{2,4}$, Fernanda Mus Aguiar ${ }^{5}$, Eliandra Lima ${ }^{2,4}$, Valéria Centeno Freitas ${ }^{1}$, Beatriz D. Schaan ${ }^{2,4}$ and Miguel Gus ${ }^{1,3^{*}}$

\begin{abstract}
Background: Blood pressure (BP) variability is associated with target organ damage in hypertension and diabetes. The $24 \mathrm{~h}$ ambulatory blood pressure monitoring (24 h-ABPM) has been proposed as an evaluation for BP variability using several indexes [standard deviation (SD) of mean BP, coefficient of variation (CV), BP variation over time (time-rate index)].

Methods: We evaluated the association between BP variability measured by 24 h-ABPM indexes and echocardiographic variables in a cross-sectional study in 305 diabetic-hypertensive patients.

Results: Two groups were defined by the median $(0.55 \mathrm{mmHg} / \mathrm{min})$ of time-rate systolic BP (SBP) index and classified as low or high variability. Age was $57.3 \pm 6.2$ years, 196 (64.3\%) were female. Diabetes duration was 10.0 (5.0-16.2) years, HbA1c was $8.2 \pm 1.9 \%$. Baseline clinical characteristics were similar between low $(n=148)$ and high $(n=157)$ variability groups. Office SBP and systolic 24 h-ABPM were higher in the high variability group (139.9 $\mathrm{mmHg}$ vs $146.0 \mathrm{mmHg}, P=0.006 ; 128.3 \mathrm{mmHg}$ vs $132.9 \mathrm{mmHg}, P=0.019$, respectively). Time-rate index, SD and CV of SBP, were higher in high variability group $(P<0.001 ; P<0.001$ and $P=0.003$, respectively). Time-rate index was not independently associated with the echocardiography's variables in multiple linear model when adjusting for age, $24 \mathrm{~h}$-ABPM, diabetes duration and HbA1c. The multiple linear regression model revealed that the significant and independent determinants for septum thickness, relative wall thickness and posterior wall thickness (parameters of left ventricular hypertrophy) were: age ( $p=0.025 ; p=0.010 ; p=0.032$, respectively) and $24 \mathrm{~h}-\mathrm{SBP}$ $(p<0.001$ in the three parameters).
\end{abstract}

Conclusion: BP variability estimated by $24 \mathrm{~h}-\mathrm{ABPM}$ is not independently associated with echocardiographic parameters in diabetic-hypertensive patients.

Keywords: Diabetes mellitus type 2, Echocardiography, Hypertension

\footnotetext{
* Correspondence: mgus@terra.com.br

${ }^{1}$ Cardiology, Hospital de Clínicas de Porto Alegre, Rua Ramiro Barcelos 2350,

sala 2061, 90035-003 Porto Alegre, RS, Brazil

${ }^{3}$ Postgraduate Studies Program in Cardiology, School of Medicine,

Universidade Federal do Rio Grande do Sul, Rua Ramiro Barcelos, 2400 - $2^{\circ}$

andar, Porto Alegre, RS, Brazil

Full list of author information is available at the end of the article
} 


\section{Background}

Observational studies had consistently shown the continuous relationship between office systolic and diastolic blood pressure (BP) and cardiovascular events [1]. Indeed, the causal role of high BP for cardiovascular disease was fully confirmed by clinical trials [2]. The evidence that high BP highers the risk for cardiovascular events, and the consistent reduction of these events by clinical trials of BP-lowering agents are robust proofs of the concept that high $\mathrm{BP}$ is a major cardiovascular determinant [3].

Methods of out-of-office BP measurement such as $24 \mathrm{~h}$ ambulatory BP monitoring (24 h-ABPM) evaluated in general population or in hypertensive-based longitudinal studies also showed a close relationship between $\mathrm{BP}$ elevation and cardiovascular risk [4,5]. Other parameters assessed by $24 \mathrm{~h}-\mathrm{ABPM}$, beyond the average of $\mathrm{BP}$, such as BP variability, may provide additional information regarding the cardiovascular risk $[6,7]$. Blood pressure fluctuations are a result of the interplay between external environmental stimuli, vascular environment and biological autonomic circulatory regulation [8]. Measures of BP variability can be obtained through different methods or indexes [9] and short-term BP variability over a $24 \mathrm{~h}$ period estimated from $24 \mathrm{~h}-\mathrm{ABPM}$ can be measured by a more refined estimation such as the time-rate index. This index is calculated as the mean of the absolute ratios of the differences between successive BP measures and the time (in minutes) between them. It quantifies how fast and in which direction systolic BP (SBP) values change and, thereby, is claimed to offer an insight into how steep these changes are. Cross-sectional and longitudinal studies showed an independent relationship between the time-rate index and target-organ damage or cerebrovascular events [10-13]. Echocardiographic evaluation is recommended to assess asymptomatic organ damage in hypertensive patients since left ventricular hypertrophy and diastolic dysfunction are independently associated with cardiovascular outcomes [14]. These variables could be used as surrogates to assess the possible association between BP variability and cardiovascular risk in high-risk patients.

Considering the high cardiovascular risk profile [15] and the frequent occurrence of autonomic dysfunction in diabetic patients, [16] the relationship between the short-term variability over a $24 \mathrm{~h}$ period and target-organ damage should be estimated. This relationship has not been well evaluated in observational studies [17]. The present cross-sectional study aims to address this issue by evaluating the potential association between variables of BP variability including the time-rate index of $24 \mathrm{~h}$-SBP and echocardiographic parameters of cardiac chambers, left ventricular hypertrophy and diastolic function.

\section{Methods}

This is a cross-sectional study conducted in the outpatient clinic of a tertiary hospital (Hospital de Clínicas de Porto Alegre/Brazil), from April 2010 to December 2011. The data came from a larger study that aimed to assess cardiovascular risk in diabetic hypertensive patients through non-invasive methods [18-20]. The study was approved by the Ethics Committee of Porto Alegre Clinics Hospital (Hospital das Clínicas de Porto AlegreGPPG 09-636) which is accredited by the Office of Human Research Protections as an Institutional Review Board. All participants signed an informed consent form before entering the study.

The study population was selected from a consecutive sample of 2342 screened patients. Patients were included in this analysis if they had a previous diagnosis of type 2 diabetes mellitus and hypertension, as ascertained by their personal history of the diseases or because they were using antidiabetic and/or antihypertensives for treatment, and were less than 65 years of age. Exclusion criteria were body mass index (BMI) $\geq 35 \mathrm{~kg} / \mathrm{m},{ }^{2}$ cancer, arrhythmias (e.g., atrial fibrillation) that could interfere with $\mathrm{BP}$ measurement and $24 \mathrm{~h}-\mathrm{ABPM}$ recordings. According to these criteria, 351 patients were included (Fig. 1).

Patients who met the inclusion criteria and agreed to participate underwent a demographic and clinical baseline data collection, including the assessment of duration of diabetes and hypertension and its known chronic complications, smoking habits, previous cardiovascular diseases, medication in use, BMI, and office BP levels.

Blood pressure was measured after 15 min of rest with an automatic sphygmomanometer (OMRON Comfort III Visomat Incoterm, Germany). High office BP levels were defined as office BP higher than 140/90 $\mathrm{mmHg}$.

Among the 351 selected individuals, $93.1 \%(n=327)$ underwent 24 h-ABPM (Spacelabs 90207, Redmond, WA) on an usual working day, performed at up to four months after the initial evaluation (approximately $75 \%$ of patients had full evaluation within 30 days). Readings were obtained automatically at 15-min intervals during the day and at 20-min intervals during the night for the duration of the $24 \mathrm{~h}-\mathrm{ABPM}$ period. Cuff size was chosen according to arm circumference. Daytime was defined as the interval between 06:00-22:00 $\mathrm{h}$ and nighttime was the interval between 22:00-06:00 h. Individuals with less than 6 and 18 measures during the night and the day periods, respectively $(n=24)$ were excluded from further analysis. All individuals were instructed to rest or sleep during the nighttime and to maintain their usual activities during daytime. Based on the results of the $24 \mathrm{~h}$ ABPM, the mean $24 \mathrm{~h}-\mathrm{SBP}$ and diastolic BP (DBP) were calculated for each patient. We calculated three different parameters of SBP variability: the standard deviation of mean (SD), coefficient of variation $(\mathrm{CV}=\mathrm{SD} /$ mean 


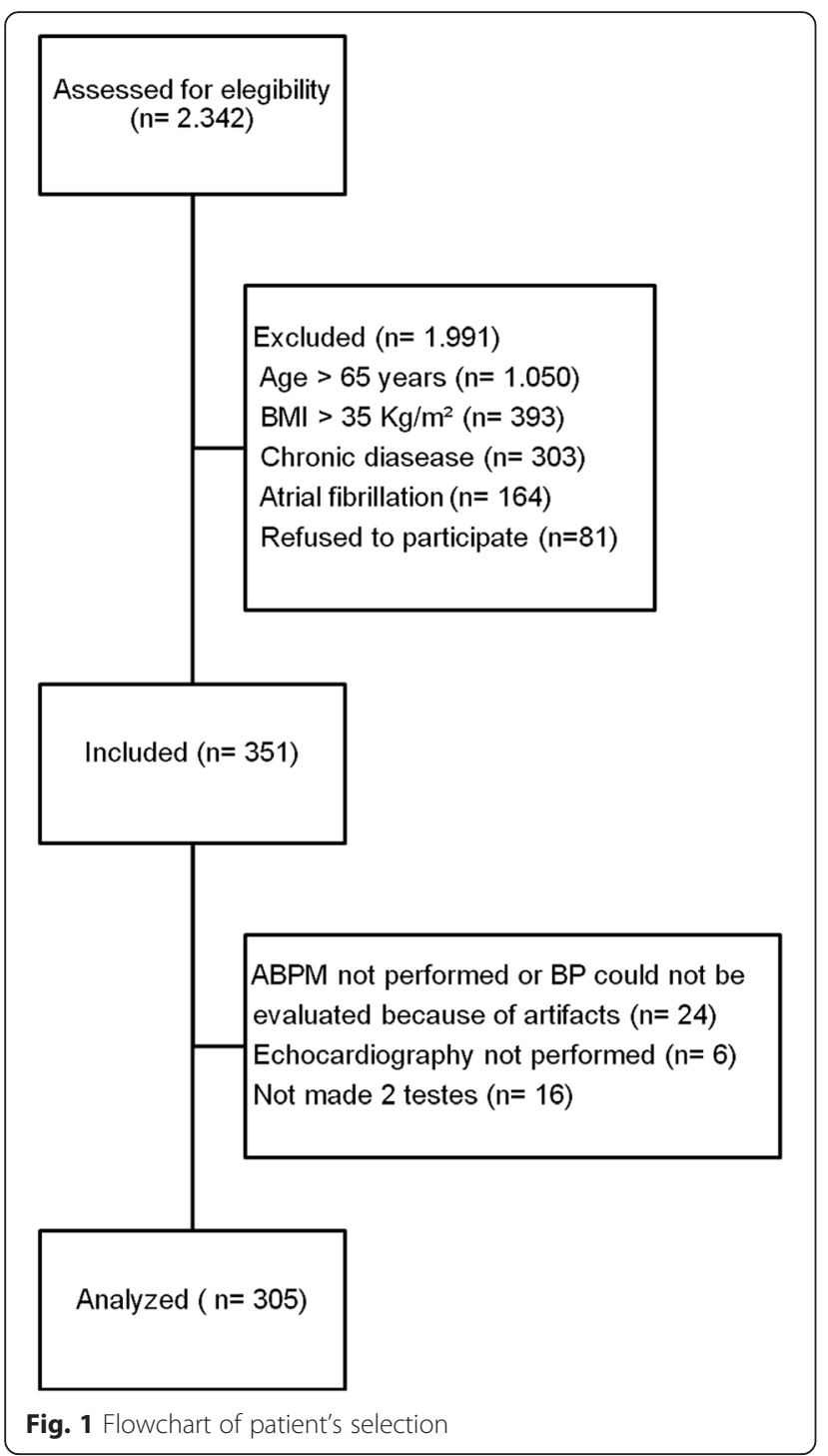

pressure $\times 100 \%)$ and rate of change in SBP over time ( $\mathrm{mmHg} / \mathrm{min})$, defined as the first derivative values of SBP by time (time-rate index). This index allows the calculation of the sum of angular coefficients and aims to measure how fast or how slow and which direction SBP values change. The measure was calculated using the following formula [9]:

$$
R=|\bar{r}|=\frac{\sum_{i=1}^{N-1}\left|r_{i}\right|}{N-1}
$$

In the formula, $r$ is the rate of BP variability over time (considering the differences between BP measurements in each time interval) and $N$ is the number of recordings.

Echocardiography was performed in $98.3 \%(n=345)$ of patients by a single investigator, usually on the same day of the $24 \mathrm{~h}$-ABPM. Images were obtained using a commercially available instrument (GE Healthcare
VIVID 7, Buckinghamshire, UK) equipped with a $4 \mathrm{MHz}$ transducer, according to the recommendations of the American Society of Echocardiography, [21] using three consecutive cardiac cycles. Standard parasternal and apical views were performed with subjects in the partial left decubitus position. Left ventricular volumes and ejection fraction were calculated by the Simpson's formula; ventricular mass was calculated based on wall thickness adjusted in two ways: to the body surface area and indexed to body height to the power of 2.7. Relative wall thickness (RWT) was defined as "septum + posterior wall (PW) thickness" divided by "left ventricular diastolic diameter". Diastolic function was evaluated based upon mitral inflow doppler measurements (maximum early flow velocity in diastole- $\mathrm{E}$ wave- and maximum late velocity flow in diastole- A wave). Peak early (E') and peak late (A') tissue Doppler velocities were assessed at the mitral annulus, determining values as the average of septal and lateral wall measurements. The variables septum and PW thickness, RWT and left ventricular mass índex were used for categorical analyzes on the prevalence of left ventricular hypertrophy, adopting the reference values proposed by the American Society of Echocardiography [21]. Hypertrophy was defined considering the normal range of $1.0 \mathrm{~cm}$ to septum obtained in a representative sample of adults in the city of Porto Alegre, as previously described [22].

Fasting blood samples were collected for laboratory analysis using commercial kits. Plasma glucose was evaluated by a glucose oxidase method, serum creatinine by Jaffé's reaction, and glycated hemoglobin (HbA1c) by ion-exchange HPLC (Merck-Hitachi L-9100 $\mathrm{HbA}_{1 \mathrm{c}}$ analyzer; reference range 4.8-6.0 \%; Merck, Darmstadt, Germany). Serum total cholesterol and triglycerides were measured by enzymatic-colorimetric methods (Merck Diagnostica, Germany; Boehringer Mannheim, Argentina), and High-density lipoprotein (HDL) cholesterol by a homogeneous direct method (autoanalyzer, ADVIA 1650). Low-density lipoprotein (LDL) cholesterol was calculated using Friedewald's formula [23]. Glomerular filtration rate was calculated using the MDRD (Modification of diet in renal disease) equation [24]. C-Reactive Protein was measured using an ultrasensitive assay by nephelometry (Bayer nephelometer, Leverkusen, Germany), capable of evaluating values in the range of $1-4 \mathrm{mg} / \mathrm{l}$. Urinary albumin excretion was evaluated by immunoturbidimetry (MICROALB- AMES Kit, CA, USA). Abnormal albuminuria was defined as albuminuria of $17 \mathrm{mg} / \mathrm{dl}$ or more [25].

\section{Statistical analyses}

The comparison groups were defined by the median of time-rate index of $24 \mathrm{~h}-\mathrm{SBP}$ and classified as low and high variability of time-rate index: values $\leq 0.54 \mathrm{mmHg} / \mathrm{min}$ or $\geq$ $0.55 \mathrm{mmHg} / \mathrm{min}$, respectively. Comparisons were tested by Pearson's chi-square test, Student's $t$ test, and Mann- 
Whitney test. Logistic regression models and multiple linear regression were used to evaluate the association between echocardiography's variables and parameters of variability of $24 \mathrm{~h}-\mathrm{SBP}$. Age, $24 \mathrm{~h}$-SBP, diabetes duration (years) and HbA1c were included in models. Continuous variables are expressed as mean $\pm \mathrm{SD}$ or median and interquartile range. Categorical variables are expressed as number (\%).

Sample size calculation was based upon the mean differences in two echocardiographic variables of septum

Table 1 Clinical characteristics of the participants according to blood pressure variability

\begin{tabular}{|c|c|c|c|c|}
\hline Characteristics & $\begin{array}{l}\text { Total sample } \\
(n=305)\end{array}$ & $\begin{array}{l}\text { Low variability } \\
(n=148)\end{array}$ & $\begin{array}{l}\text { High variability } \\
(n=157)\end{array}$ & $P$ \\
\hline Age & $57.3 \pm 6.2$ & $57.9 \pm 6.4$ & $57.5 \pm 6.0$ & 0.565 \\
\hline Female gender & $196(64.3)$ & $99(66.9)$ & $97(61.8)$ & 0.354 \\
\hline Caucasian & $207(68.3)$ & $99(66.9)$ & $110(70.1)$ & 0.334 \\
\hline Duration of diabetes (years) & $10(5-16)$ & $10(5-16)$ & $10(5-17)$ & 0.466 \\
\hline Weight & $78.3 \pm 12.8$ & $79.6 \pm 13.6$ & $77.3 \pm 12.1$ & 0.116 \\
\hline BMI $\left(\mathrm{kg} / \mathrm{m}^{2}\right)$ & $30.1 \pm 3.8$ & $30.7 \pm 3.9$ & $29.6 \pm 3.7$ & 0.013 \\
\hline Waist circumference & $102 \pm 9$ & $103 \pm 10$ & $101 \pm 91$ & 0.203 \\
\hline Neck circumference & $38.5 \pm 3.5$ & $38.5 \pm 3.3$ & $38.6 \pm 3.7$ & 0.874 \\
\hline \multicolumn{5}{|l|}{ Smoking } \\
\hline No & $163(33.4)$ & $81(55.9)$ & $82(52.2)$ & \multirow[t]{3}{*}{0.803} \\
\hline Yes & $38(12.6)$ & $18(12.4)$ & $20(12.7)$ & \\
\hline Former & $101(54)$ & $46(31.7)$ & $55(35.0)$ & \\
\hline With any previous cardiovascular comorbidity ${ }^{a}$ & $70(23)$ & $31(20.9)$ & $39(24.8)$ & 0.404 \\
\hline Abnormal albuminuriab & $88(28.9)$ & $43(29.0)$ & $45(28.7)$ & 0.520 \\
\hline Myocardial infarction & $38(12.6)$ & $16(11.0)$ & $22(14.1)$ & 0.410 \\
\hline Coronary artery bypass grafting & $13(4.3)$ & $4(2.8)$ & $9(5.8)$ & 0.199 \\
\hline $\mathrm{PCl}$ & $25(8.3)$ & $9(6.3)$ & $16(10.3)$ & 0.210 \\
\hline Heart failure & $26(8.7)$ & $15(10.3)$ & $11(7.1)$ & 0.318 \\
\hline Stroke & $28(9.5)$ & 19 (13.5) & $9(5.8)$ & 0.024 \\
\hline \multicolumn{5}{|l|}{ Medications } \\
\hline Insulin & $143(47.2)$ & $58(39.5)$ & $85(54.5)$ & 0.009 \\
\hline 1 Antihypertensive drug & $50(16.4)$ & $22(14.9)$ & $28(17.8)$ & 0.537 \\
\hline 2 Antihypertensive drug & $87(28.5)$ & $38(25.7)$ & $49(31.2)$ & 0.311 \\
\hline$\geq 3$ Antihypertensive drug & $168(55.1)$ & $88(59.5)$ & $80(51)$ & 0.167 \\
\hline Antiplatelet & $199(65.9)$ & $101(68.7)$ & $98(63.2)$ & 0.315 \\
\hline Statins & $210(69.8)$ & $113(76.9)$ & $97(63)$ & 0.009 \\
\hline \multicolumn{5}{|l|}{ Laboratory characteristics } \\
\hline HbA1c (\%) & $8.2 \pm 1.9$ & $8.2 \pm 1.9$ & $8.3 \pm 1.9$ & 0.743 \\
\hline Fasting plasma glucose (mg/dL) & $159.3 \pm 72.4$ & $162.2 \pm 74.8$ & $156.7 \pm 70.4$ & 0.533 \\
\hline Total cholesterol (mg/dL) & $178.8 \pm 42.4$ & $176.6 \pm 38.7$ & $180.7 \pm 45.6$ & 0.426 \\
\hline HDL cholesterol (mg/dL) & $41.9 \pm 11.8$ & $42.1 \pm 12.3$ & $41.8 \pm 11.4$ & 0.793 \\
\hline Triglycerides (mg/dL) & $155(103.8-234)$ & $152(103-216)$ & $163(104-248)$ & 0.534 \\
\hline GFR $\left(\mathrm{mL} / \mathrm{min} / 1.73 \mathrm{~m}^{2}\right)$ & $90.4 \pm 26.8$ & $89.1 \pm 26.4$ & $91.7 \pm 27.2$ & 0.401 \\
\hline
\end{tabular}

The comparison groups were defined by the median of time-rate index of $24 \mathrm{~h}$ systolic BP and classified as low and high variability of time-rate index: values $\leq 0.54$ or $\geq 0.55$, respectively

$B M I$ body mass index; $P C I$ percutaneous coronary intervention; GFR estimated glomerular filtration rate calculated by the MDRD equation; BP: blood pressure ${ }^{a}$ With previous cardiovascular comorbidity = when reported at least one previous cardiovascular disease (Myocardial infarction; Coronary artery bypass grafting; PCl; Heart failure; Stroke)

${ }^{\mathrm{b}}$ Abnormal albuminuria, defined by albuminuria $>17 \mathrm{mg} / \mathrm{L}$

Continuous variables are expressed as mean \pm standard deviation or median (interquartile range $\left(\mathrm{p}_{25}-\mathrm{p}_{75}\right)$ ). Categorical variables are expressed as number $(\%)$. Comparisons (low variability vs. high variability) were tested by Pearson's $x^{2}$ test, Student $t$ test and Mann-Whitney test 
and E/E', between low and high variability. Considering the $1: 1$ proportion in low and high variability groups, a SD of $0.17 \mathrm{~cm}$, an alpha error of $5 \%$, and power of $90 \%$ to detect a $10 \%$ increase in the septum, the sample size estimation was 124 patients (62 in each group). For the E/E' ratio we considered a SD of 3.6, considering the same proportion, alpha error and power to detect a $15 \%$ of difference between groups, the sample size estimation was 162 patients (81 in each group).

Logarithmic transformation was applied to albuminuria before parametric tests were applied. $P$ values $<0.05$ (twotailed) were considered to be statistically significant. Statistical Package for Social Science (SPSS, Chicago, IL.) version 18.0 was used for the analyses.

\section{Results}

A total of 305 patients was evaluated. The characteristics of the subjects studied, grouped as low and high variability (time-rate index of $24 \mathrm{~h}$-SBP) are presented in Table 1. Patients were $57.3 \pm 6.2$ years, $196(64.3 \%)$ were women, and 207 (68.3\%) were caucasian. Body mass index, previous history of stroke, use of statins were higher in low variability group; insulin use was higher in the high variability group. Previous history of any cardiovascular disease was present in 88 patients (29.4\%), but was similar between groups. The other characteristics were similar in both groups.

Office BP recordings and $24 \mathrm{~h}-\mathrm{ABPM}$ parameters are presented in Table 2. Systolic BP was $6.1 \mathrm{mmHg}$ $(P=0.006)$ higher in the high variability as compared to the low variability group, as well as mean and daytime SBP of 24 h-ABPM $(P=0.019$ and $P<0.001$, respectively).
The time-rate index of $24 \mathrm{~h}$-SBP was higher in the high variability group as compared to the low variability group $(0.648 \mathrm{mmHg} / \mathrm{min}$ vs $0.459 \mathrm{mmHg} / \mathrm{min}$, respectively; $P<0.001)$, such as the other parameters of variability, SD SBP (13.76 $\mathrm{mmHg}$ vs $11.37 \mathrm{mmHg}$, respectively) and CV of SBP (10.99 \% vs $8.89 \%$, respectively) were higher in the group of high variability when compared to the group of low variability.

Echocardiographic measurements are presented in Table 3. From the total sample, 178 patients $(58.4 \%)$ had ventricular hypertrophy considering a cut-off point of $1 \mathrm{~cm}$. When stratified by gender and considering the threshold values for the population of Porto Alegre [22] the proportions were $93.6 \%$ and $95.9 \%$ for men and women, respectively. Considering de diastolic function and the cut-off point $>8$ for the E/E' ratio, 234 patients (76.8 \%) showed abnormal values [21].

The time-rate index of SBP was not associated with the echocardiography's variables in multiple linear model when adjusting for age, $24 \mathrm{~h}$-SBP, duration of diabetes (years) and HbA1c (Table 4). The multiple linear regression model revealed that the significant and independent determinants for septum thickness, RWT and PW thickness (parameters of left ventricular hypertrophy) were: age $(p=0.025 ; p=0.010 ; p=0.032$, respectively) and 24 h-SBP $(p<0.001$ in the three parameters). Considering the parameters of diastolic function, age was the only variable that was significantly associated with isovolumetric relaxation time (IVRT) and E/E' ratio.

The other variability parameters were also analyzed, but also showed no significant differences between low and high variability groups.

Table 2 Office blood pressure recordings and ambulatory blood pressure monitoring parameters of the participants according to blood pressure variability

\begin{tabular}{|c|c|c|c|c|}
\hline & $\begin{array}{l}\text { Total sample } \\
(n=305)\end{array}$ & $\begin{array}{l}\text { Low variability } \\
(n=148)\end{array}$ & $\begin{array}{l}\text { High variability } \\
(n=157)\end{array}$ & $P$ \\
\hline Office SBP (mmHg) & $143.0 \pm 19.3$ & $139.9 \pm 17.5$ & $146.0 \pm 20.6$ & 0.006 \\
\hline Office DBP (mmHg) & $82.0 \pm 10.6$ & $81.4 \pm 10.6$ & $82.6 \pm 10.7$ & 0.355 \\
\hline 24 h-ABPM SBP (mmHg) & $130.6 \pm 16.9$ & $128.3 \pm 14.7$ & $132.9 \pm 18.6$ & 0.019 \\
\hline 24 h-ABPM DBP (mmHg) & $76.5 \pm 9.3$ & $75.7 \pm 10.0$ & $77.3 \pm 8.6$ & 0.144 \\
\hline Daytime 24-ABPM SBP (mmHg) & $133.7 \pm 15.9$ & $130.5 \pm 14.5$ & $136.9 \pm 16.7$ & $<0.001$ \\
\hline Daytime 24-ABPM DBP (mmHg) & $78.9 \pm 10.0$ & $77.9 \pm 10.4$ & $79.9 \pm 9.7$ & 0.080 \\
\hline Nighttime 24-ABPM SBP (mmHg) & $124.0 \pm 18.3$ & $122.6 \pm 18.4$ & $125.5 \pm 18.2$ & 0.169 \\
\hline Nighttime 24-ABPM DBP (mmHg) & $69.6 \pm 10.7$ & $69.8 \pm 11.2$ & $69.5 \pm 10.4$ & 0.817 \\
\hline Time-rate index SBP (mmHg/min) & $0.557 \pm 0.116$ & $0.459 \pm 0.058$ & $0.648 \pm 0.075$ & $<0.001$ \\
\hline SD SBP $(\mathrm{mmHg})$ & $12.60 \pm 4.40$ & $11.37 \pm 4.24$ & $13.76 \pm 4.25$ & $<0.001$ \\
\hline CV SBP (\%) & $9.97 \pm 6.29$ & $8.89 \pm 3.16$ & $10.99 \pm 8.10$ & 0.003 \\
\hline
\end{tabular}

The comparison groups were defined by the median of time-rate index of $24 \mathrm{~h}$ systolic BP and classified as low and high variability of time-rate index: values $\leq 0.54$ or $\geq 0.55$, respectively

$B P$ blood pressure, $A B P M$ ambulatory blood pressure monitoring, $S B P$ systolic blood pressure, $D B P$ diastolic blood pressure, $S D S B P$ standard deviation of mean SBP, CV SBP coefficient of variability SBP

Data are expressed as mean \pm standard deviation. Comparisons (low variability vs. high variability) were tested by Student $t$ test 
Table 3 Echocardiographic parameters of the participants according to blood pressure variability

\begin{tabular}{|c|c|c|c|c|}
\hline & $\begin{array}{l}\text { Total sample } \\
(n=305)\end{array}$ & $\begin{array}{l}\text { Low variability } \\
(n=148)\end{array}$ & $\begin{array}{l}\text { High variability } \\
(n=157)\end{array}$ & $P$ \\
\hline \multicolumn{5}{|l|}{ Cardiac chamber diameters } \\
\hline Aorta $(\mathrm{cm})$ & $3.16 \pm 0.36$ & $3.17 \pm 0.37$ & $3.14 \pm 0.34$ & 0.383 \\
\hline Left atrium (cm) & $3.80 \pm 0.45$ & $3.83 \pm 0.46$ & $3.77 \pm 0.42$ & 0.238 \\
\hline LVSD (cm) & $2.99 \pm 0.40$ & $2.99 \pm 0.42$ & $2.99 \pm 0.39$ & 0.898 \\
\hline LVDD (cm) & $4.58 \pm 0.47$ & $4.61 \pm 0.47$ & $4.55 \pm 0.46$ & 0.291 \\
\hline Right ventricle (cm) & $2.15 \pm 0.28$ & $2.16 \pm 0.27$ & $2.13 \pm 0.28$ & 0.470 \\
\hline LVEF (\%) & $64.66 \pm 5.27$ & $64.90 \pm 5.09$ & $64.42 \pm 5.44$ & 0.856 \\
\hline \multicolumn{5}{|l|}{ Left ventricular hypertrophy } \\
\hline RWT & $0.43 \pm 0.08$ & $0.43 \pm 0.09$ & $0.43 \pm 0.07$ & 0.780 \\
\hline Septum thickness (cm) & $1.00 \pm 0.17$ & $1.00 \pm 0.18$ & $0.99 \pm 0.16$ & 0.676 \\
\hline PW Thickness (cm) & $0.95 \pm 0.15$ & $0.95 \pm 0.15$ & $0.95 \pm 0.15$ & 0.683 \\
\hline LVMI $\left(\mathrm{g} / \mathrm{m}^{2}\right)$ & $99.19 \pm 30.24$ & $100.38 \pm 32.24$ & $98.08 \pm 28.33$ & 0.513 \\
\hline LAVI $\left(\mathrm{mL} / \mathrm{m}^{2}\right)$ & $29.14 \pm 9.98$ & $29.32 \pm 10.64$ & $28.97 \pm 9.34$ & 0.497 \\
\hline \multicolumn{5}{|l|}{ Diastolic function } \\
\hline E wave velocity (m/s) & $0.98 \pm 0.18$ & $0.97 \pm 0.20$ & $0.99 \pm 0.16$ & 0.494 \\
\hline A wave velocity (m/s) & $0.82 \pm 0.23$ & $0.82 \pm 0.24$ & $0.82 \pm 0.23$ & 0.976 \\
\hline E wave DT $(\mathrm{m} / \mathrm{s})$ & $235.28 \pm 44.16$ & $233.07 \pm 45.26$ & $237.37 \pm 43.13$ & 0.397 \\
\hline A wave length $(\mathrm{cm} / \mathrm{s})$ & $179.15 \pm 42.30$ & $176.44 \pm 42.15$ & $181.71 \pm 42.41$ & 0.292 \\
\hline E/A ratio $(m)$ & $0.95 \pm 0.30$ & $0.94 \pm 0.28$ & $0.95 \pm 0.33$ & 0.795 \\
\hline$E^{\prime}$ wave velocity $(\mathrm{m} / \mathrm{s})$ & $0.07 \pm 0.03$ & $0.07 \pm 0.01$ & $0.08 \pm 0.04$ & 0.387 \\
\hline E/E' ratio & $11.10 \pm 3.66$ & $11.22 \pm 4.08$ & $10.99 \pm 3.22$ & 0.586 \\
\hline IVRT (m/s) & $109.22 \pm 18.15$ & $109.42 \pm 19.11$ & $109.04 \pm 17.24$ & 0.855 \\
\hline
\end{tabular}

The comparison groups were defined by the median of time-rate index of $24 \mathrm{~h}$ systolic BP and classified as low and high variability of time-rate index: values $\leq 0.54$ or $\geq 0.55$, respectively

LVSD left ventricular systolic diameter, $L V D D$ left ventricular diastolic diameter, $L V E F$ left ventricular ejection fraction, $R W T$ relative wall thickness, $P W$ posterior wall, LVMI left ventricular mass index, LAVI left atrial volume index, IVTR isovolumetric relaxation time, DT E wave deceleration time, BP blood pressure

Data are expressed as mean \pm standard deviation. Comparisons (low vs. high variability) were tested by Student $t$ test

\section{Discussion}

The results of this cross-sectional study in a sample of hypertensive-diabetic patients did not show associations between BP variability assessed through 24 h-ABPM with echocardiographic variables related to diastolic function, left ventricular hypertrophy and cardiac chamber diameters. The variables significantly associated with parameters of left ventricular hypertrophy (septum thickness, RWT and PW thickness) and diastolic function (IVRT and E/E') were age and $24 \mathrm{~h}-\mathrm{SBP}$, and the only parameter associated with diastolic function (IVRT and E/E') was age.

Cross-sectional and longitudinal studies showed a positive association between BP variability and cardiovascular risk in pure hypertensive patients. The identification of higher risk patients through variables beyond the absolute values of BP could have practical applications. High risk patients with high BP variability could be chosen to have lower BP targets. Moreover, there is some evidence of a class difference effect between antihypertensive drugs in the within-individual visit-to-visit variability of BP. This potential effect on BP variability could be the guide to an optimal antihypertensive treatment in higher risk patients [26]. In a prospective study, Zis et al. [13] reported that patients with higher $24 \mathrm{~h}$ rates of SBP variation assessed by the time-rate index were more likely to have a negative neurologic outcome at 1 year after stroke. Moreover, a cross-sectional study with 539 subjects showed an independent association between timerate index of $24 \mathrm{~h}$-SBP and intima-media thickness of the carotid measured by ultrasound [9]. However, the authors did not define the cutoff points of BP variability normality. In another cross-sectional study $24 \mathrm{~h}-\mathrm{BP}$ variability of SBP was independently associated with impaired renal function [12].

The association of time-rate index of SBP with echocardiographic parameters was previously studied by Zakopoulos et al. in a cross-sectional study. They demonstrated that a $0.1 \mathrm{mmHg} / \mathrm{min}$ increase in the 
Table 4 Association between time-rate index and echocardiography's variables in multiple linear model

\begin{tabular}{|c|c|c|c|}
\hline & Beta & S.E. & $P$ \\
\hline \multicolumn{4}{|l|}{ Left ventricular hypertrophy } \\
\hline \multicolumn{4}{|l|}{ Septum thickness (cm) } \\
\hline Time-rate SBP (mmHg/min) & -0.029 & 0.086 & 0.739 \\
\hline Age (years) & 0.004 & 0.002 & 0.025 \\
\hline 24 h-ABPM SBP (mmHg) & 0.002 & 0.001 & $<0.001$ \\
\hline Diabetes duration (years) & $<0.001$ & 0.001 & 0.510 \\
\hline $\mathrm{HbA1c}(\%)$ & 0.003 & 0.005 & 0.635 \\
\hline \multicolumn{4}{|l|}{ RWT } \\
\hline Time-rate index SBP (mmHg/min) & -0.044 & 0.041 & 0.277 \\
\hline Age (years) & 0.002 & 0.001 & 0.010 \\
\hline 24 h-ABPM SBP (mmHg) & 0.001 & $<0.001$ & $<0.001$ \\
\hline Diabetes duration (years) & 0.001 & 0.001 & 0.134 \\
\hline $\mathrm{HbA1c}(\%)$ & 0.001 & 0.003 & 0.583 \\
\hline \multicolumn{4}{|l|}{ PW Thickness } \\
\hline Time-rate SBP (mmHg/min) & 0.006 & 0.075 & 0.937 \\
\hline Age (years) & 0.003 & 0.001 & 0.032 \\
\hline 24 h-ABPM SBP (mmHg) & 0.002 & $<0.001$ & $<0.001$ \\
\hline Diabetes duration (years) & $<0.001$ & 0.001 & 0.591 \\
\hline $\mathrm{HbA1c}(\%)$ & $<0.001$ & 0.005 & 0.977 \\
\hline \multicolumn{4}{|l|}{ Diastolic function } \\
\hline \multicolumn{4}{|l|}{ IVRT (m/s) } \\
\hline Time-rate SBP (mmHg/min) & -5.243 & 9.248 & 0.571 \\
\hline Age (years) & 0.889 & 0.174 & $<0.001$ \\
\hline 24 h-ABPM SBP (mmHg) & 0.041 & 0.054 & 0.443 \\
\hline Diabetes duration (years) & -0.139 & 0.130 & 0.284 \\
\hline $\mathrm{HbA1c}(\%)$ & 0.644 & 0.581 & 0.269 \\
\hline \multicolumn{4}{|l|}{ E/E' ratio } \\
\hline Time-rate SBP (mmHg/min) & 0.419 & 1.911 & 0.826 \\
\hline Age (years) & 0.128 & 0.036 & $<0.001$ \\
\hline 24 h-ABPM SBP (mmHg) & 0.004 & 0.011 & 0.744 \\
\hline Diabetes duration (years) & 0.003 & 0.027 & 0.899 \\
\hline HbA1c (\%) & -0.042 & 0.120 & 0.727 \\
\hline
\end{tabular}

$B P$ blood pressure, SBP systolic blood pressure, $A B P M$ ambulatory blood pressure monitoring, HbA1C glycated hemoglobin, RWT relative wall thickness, $P W$ posterior wall, IVRT isovolumetric relaxation time. Adjusted for age, 24 h-ABPM-hour ABPM SBP, duration of diabetes (years) and HbA1c

daytime rate of SBP variation was associated with an increment of $7.087 \mathrm{~g}$ (95 \% confidence interval 4.775-9.399) in the left ventricular mass [27]. Short-term BP variability can be estimated through different indexes derived from 24 h-ABPM. Mena et. al in a longitudinal study with 312 hypertensive patients identified an independent relationship between the "average real variability index", an index that also averages the absolute differences of consecutive measurements, and cardiovascular events. This positive relationship was not identified with the SD of the mean SBP [28]. Despite these evidences, guidelines do not recommend the use of BP variability parameters for routine clinical use in hypertensive patients, mainly because the lack of threshold values of BP variability and the absence of evidences of any intervention effect [7, 29].

Diabetes is associated with higher values of short-term BP variability [30]. Ozawa et al. in a prospective study with diabetic hypertensive patients demonstrated higher values of $24 \mathrm{~h}-\mathrm{SBP}$ and DBP variability than the nondiabetic hypertensive group (SD of mean SBP, $18.2 \mathrm{mmHg}$ vs $14.5 \mathrm{mmHg} ; p=0.041$ and SD of mean DBP, $11.5 \mathrm{mmHg}$ vs $9.6 \mathrm{mmHg} ; p=0.042$ ). A prospective study in patients with type 2 diabetes has shown that nighttime BP variability estimated by SD of the nighttime SBP and DBP was an independent predictor of future incidence of cardiovascular events [31]. However in other reports in diabetic patients, especially with nephropathy and sympathovagal imbalance, there was an absence of nighttime BP falling because of functional impairment of the autonomic nervous system [32, 33]. Unfortunately, information on diabetic neuropathy, which could have influenced the BP variability, was not available in our study.

In the present study we analyzed the relationship of short-term BP variability and echocardiographic parameters in a high risk sample. Diabetic hypertensive patients have approximately twice the risk of developing cardiovascular events when compared to purely hypertensive patients. Moreover, $56 \%$ of our sample had history of previous cardiovascular disease, the median duration of diabetes was 10 years, the mean HbA1c was $8.2 \pm 1.9 \%$ and almost $60 \%$ had left ventricular hypertrophy. This high-risk profile of the subjects evaluated can explain our negative results, as parameters of BP variability may not add cardiovascular risk information beyond age or $B P$ values in such a high risk sample.

Certain limitations of the present study should be acknowledged. Firstly, we quantified the rate of BP changes using discontinuous $24 \mathrm{~h}-\mathrm{ABPM}$ techniques, which cannot adequately assess short-lasting BP fluctuations and can only provide some insight into slow and relatively 'long-term' BP oscillations. Secondly, the echocardiographic phenotypes assessed are not in fact endpoints. However, in longitudinal studies, these echocardiographic abnormalities have been associated with hard outcomes. Several studies have also confirmed the prognostic significance of left ventricular hypertrophy and diastolic dysfunction [34, 35]. Therefore, the detection and quantification of these echocardiographic variables seems to be relevant in the monitoring of targetorgan damage in diabetic hypertensive patients.

\section{Conclusion}

In conclusion, in a diabetic hypertensive high risk sample, $\mathrm{BP}$ variability estimated by time-rate índex of SBP was not 
independently associated with echocardiographic parameters of left ventricular hypertrophy or diastolic function. The use of BP variability for risk stratification beyond the absolute level of BP in this clinical setting should be questioned. Prospective studies in diabetic hypertensive patients with hard outcomes could better confirm our findings.

\section{Abbreviations}

24 h-ABPM: 24 h ambulatory BP monitoring; BMl: body mass index; BP: blood pressure; CV: coefficient of variation; DBP: diastolic BP; HbA1c: glycated hemoglobin; HDL: high-density lipoprotein; IVRT: isovolumetric relaxation time; LDL: low-density lipoprotein; PW: posterior wall; RWT: relative wall thickness; SBP: systolic BP; SD: standard deviation.

\section{Competing interests}

The authors declare that they have no competing interests.

\section{Authors' contributions}

DM collected, analyzed data and wrote manuscript. $L L, M S, P L, A B, F A$, EL, VF and DM performed the experiments and gathered the data. MG and BDS conceived the study, arranged the collaboration, revised the manuscript, edited and compiled the final version for submission. All authors read, approved the final manuscript and agree for the publication.

\section{Acknowledgments}

Supported by Fundo de Incentivo à Pesquisa e Eventos (FIPE) of the Hospital de Clínicas de Porto Alegre; Grant 11-0059, Conselho Nacional de Desenvolvimento Científico e Tecnológico (CNPq); Grant 472792/2009-1, Coordenação de Aperfeiçoamento de Pessoal de Nível Superior (CAPES) and by Fundação de Amparo à Pesquisa do Estado do Rio Grande do Sul (FAPERGS).

\section{Author details}

${ }^{1}$ Cardiology, Hospital de Clínicas de Porto Alegre, Rua Ramiro Barcelos 2350 sala 2061, 90035-003 Porto Alegre, RS, Brazil. Endocrine Division, Hospital de Clínicas de Porto Alegre, Rua Ramiro Barcelos 2350, sala 2061, 90035-003 Porto Alegre, RS, Brazil. ${ }^{3}$ Postgraduate Studies Program in Cardiology, School of Medicine, Universidade Federal do Rio Grande do Sul, Rua Ramiro Barcelos, $2400-2^{\circ}$ andar, Porto Alegre, RS, Brazil. ${ }^{4}$ Faculty of Medicine, Universidade Federal do Rio Grande do Sul, Rua Ramiro Barcelos, 2400 Porto Alegre, RS, Brazil. ${ }^{5}$ Universidade Federal de Ciências da Saúde de Porto Alegre, Rua Sarmento Leite, 245, 90050-170 Porto Alegre, RS, Brazil.

Received: 25 August 2015 Accepted: 31 December 2015

Published online: 08 January 2016

\section{References}

1. Lewington S, Clarke R, Qizilbash N, Peto R, Collins R. Age-specific relevance of usual blood pressure to vascular mortality: a meta-analysis of individual data for one million adults in 61 prospective studies. Lancet. 2002;360(9349):1903-13.

2. Law MR, Morris JK, Wald NJ. Use of blood pressure lowering drugs in the prevention of cardiovascular disease: meta-analysis of 147 randomised trials in the context of expectations from prospective epidemiological studies. BMJ. 2009:338:b1665.

3. Fuchs FD, Fuchs SC, Moreira LB, Gus M. Proof of concept in cardiovascular risk: the paradoxical findings in blood pressure and lipid abnormalities. Vasc Health Risk Manag. 2012;8:437-42.

4. Sega R, Facchetti R, Bombelli M, Cesana G, Corrao G, Grassi G, et al. Prognostic value of ambulatory and home blood pressures compared with office blood pressure in the general population: follow-up results from the Pressioni Arteriose Monitorate e Loro Associazioni (PAMELA) study. Circulation. 2005;111(14):1777-83.

5. Clement DL, De Buyzere ML, De Bacquer DA, de Leeuw PW, Duprez DA, Fagard RH, et al. Office versus Ambulatory Pressure Study Investigators. Prognostic value of ambulatory blood-pressure recordings in patients with treated hypertension. N Engl J Med. 2003;348(24):2407-15.

6. Pickering TG, Shimbo D, Haas D. Ambulatory blood-pressure monitoring N Engl J Med. 2006;354(22):2368-74.

7. O'Brien E, Parati G, Stergiou G. Ambulatory blood pressure measurement: what is the international consensus? Hypertension. 2013;62(6):988-94.
8. Jafar TH, Ebrahim SB. Variations in levels of blood pressure: of prognostic value or not? Am J Kidney Dis. 2008:52(4):638-41.

9. Bilo G, Parati G. Rate of blood pressure changes assessed by $24 \mathrm{~h}$ ambulatory blood pressure monitoring: another meaningful index of blood pressure variability? J Hypertens. 2011;29(6):1054-8.

10. Zakopoulos NA, Tsivgoulis G, Barlas G, Papamichael C, Spengos K, Manios E, et al. Time rate of blood pressure variation is associated with increased common carotid artery intima-media thickness. Hypertension. 2005;45(4):505-12.

11. Manios E, Stamatelopoulos K, Tsivgoulis G, Barlas G, Koroboki E, Tsagalis G, et al. Time rate of blood pressure variation: a new factor associated with coronary atherosclerosis. J Hypertens. 2011;29(6):1109-14.

12. Manios E, Tsagalis G, Tsivgoulis G, Barlas G, Koroboki E, Michas F, et al. Time rate of blood pressure variation is associated with impaired renal function in hypertensive patients. J Hypertens. 2009;27(11):2244-8.

13. Zis P, Vemmos K, Spengos K, Manios E, Zis V, Dimopoulos MA, et al. Ambulatory blood pressure monitoring in acute stroke: pathophysiology of the time rate of blood pressure variation and association with the 1-year outcome. Blood Press Monit. 2013;18(2):94-100.

14. Mancia G, Fagard R, Narkiewicz K, Redón J, Zanchetti A, Böhm M, et al. 2013 ESH/ESC Guidelines for the management of arterial hypertension: The Task Force for the management of arterial hypertension of the European Society of Hypertension (ESH) and of the European Society of Cardiology (ESC). J Hypertens. 2013;31:1281-357.

15. Gregg EW, Cheng YJ, Saydah S, Cowie C, Garfield S, Geiss L, et al. Trends in death rates among U.S. adults with and without diabetes between 1997 and 2006: findings from the National Health Interview Survey. Diabetes Care. 2012;35(6):1252-7.

16. Hsu WC, Yen AM, Liou HH, Wang HC, Chen TH. Prevalence and risk factors of somatic and autonomic neuropathy in prediabetic and diabetic patients. Neuroepidemiology. 2009;33(4):344-9.

17. Parati G, Ochoa JE, Salvi P, Lombardi C, Bilo G. Prognostic value of blood pressure variability and average blood pressure levels in patients with hypertension and diabetes. Diabetes Care. 2013;36 Suppl 2:S312-24

18. Ledur PS, Leiria LF, Severo MD, Silveira DT, Massierer D, Becker AD, et al. Perception of uncontrolled blood pressure and non-adherence to antihypertensive agents in diabetic hypertensive patients. J Am Soc Hypertens. 2013;7(6):477-83.

19. Severo MD, Leiria LF, Ledur Pdos S, Becker AD, Aguiar FM, Massierer D, et al. Association between erectile dysfunction and echocardiographic variables of ventricular hypertrophy and diastolic function in hypertensive patients with type 2 diabetes mellitus: a cross-sectional study. J Diabetes. 2014;6(6):586-94

20. Leiria LF, Severo MD, Ledur PS, Becker AD, Aguiar FM, Massierer D et al. White coat effect and masked uncontrolled hypertension in treated hypertensive-diabetic patients: Prevalence and target organ damage. J Diabetes. 2014; doi: 10.1111/1753-0407.12231. [Epub ahead of print]

21. Lang RM, Bierig M, Devereux RB, Flachskampf FA, Foster E, Pellikka PA, et al. Recommendations for chamber quantification: a report from the American Society of Echocardiography's Guidelines and Standards Committee and the Chamber Quantification Writing Group, developed in conjunction with the European Association of Echocardiography, a branch of the European Society of Cardiology. J Am Soc Echocardiogr. 2005;18(12):1440-63.

22. Schvartzman PR, Fuchs FD, Mello AG, Coli M, Schvartzman M, Moreira LB. Normal values of echocardiographic measurements. A population-based study. Arq Bras Cardiol. 2000;75(2):107-14.

23. Friedewald WT, Levy RI, Fredrickson DS. Estimation of the concentration of low-density lipoprotein cholesterol in plasma, without use of the preparative ultracentrifuge. Clin Chem. 1972;18(6):499-502.

24. Levey AS, Coresh J, Balk E, Kausz AT, Levin A, Steffes MW, et al. National Kidney Foundation practice guidelines for chronic kidney disease: evaluation, classification, and stratification. Ann Intern Med. 2003;139(2):137-47

25. Zelmanovitz T, Gross JL, Oliveira JR, Paggi A, Tatsch M, Azevedo MJ. The receiver operating characteristics curve in the evaluation of a random urine specimen as a screening test for diabetic nephropathy. Diabetes Care. 1997;20(4):516-9.

26. Webb AJ, Fischer U, Mehta Z, Rothwell PM. Effects of antihypertensive-drug class on interindividual variation in blood pressure and risk of stroke: a systematic review and meta-analysis. Lancet. 2010;375:906-15.

27. Zakopoulos NA, Tsivgoulis G, Barlas G, Spengos K, Manios E, Ikonomidis L, et al. Impact of the time rate of blood pressure variation on left ventricular mass. J Hypertens. 2006;24(10):2071-7. 
28. Mena L, Pintos S, Queipo NV, Aizpúrua JA, Maestre G, Sulbarán T. A reliable index for the prognostic significance of blood pressure variability. J Hypertens. 2005:23(3):505-11.

29. O'Brien E, Parati G, Stergiou G, Asmar R, Beilin L, Bilo G, et al. European Society of Hypertension Working Group on Blood Pressure Monitoring. European Society of Hypertension position paper on ambulatory blood pressure monitoring. J Hypertens. 2013;31(9):1731-68.

30. Ozawa M, Tamura K, Iwatsubo K, Matsushita K, Sakai M, Tsurumi-lkeya Y, et al. Ambulatory blood pressure variability is increased in diabetic hypertensives. Clin Exp Hypertens. 2008;30(3):213-24.

31. Eguchi K, Ishikawa J, Hoshide S, Pickering TG, Schwartz JE, Shimada K, et al. Night time blood pressure variability is a strong predictor for cardiovascular events in patients with type 2 diabetes. Am J Hypertens. 2009;22(1):46-51.

32. Spallone V, Bernardi L, Ricordi L, Soldà P, Maiello MR, Calciati A, et al. Relationship between the circadian rhythms of blood pressure and sympathovagal balance in diabetic autonomic neuropathy. Diabetes. 1993;42(12):1745-52.

33. Monteagudo PT, Nóbrega JC, Cezarini PR, Ferreira SR, Kohlmann Jr O, Ribeiro $A B$, et al. Altered blood pressure profile, autonomic neuropathy and nephropathy in insulin-dependent diabetic patients. Eur J Endocrinol. 1996;135(6):683-8.

34. Halley CM, Houghtaling PL, Khalil MK, Thomas JD, Jaber WA. Mortality rate in patients with diastolic dysfunction and normal systolic function. Arch Intern Med. 2011;171(12):1082-7.

35. Owan TE, Hodge DO, Herges RM, Jacobsen SJ, Roger VL, Redfield MM.

Trends in prevalence and outcome of heart failure with preserved ejection fraction. N Engl J Med. 2006;355(3):251-9.

\section{Submit your next manuscript to BioMed Central} and we will help you at every step:

- We accept pre-submission inquiries

- Our selector tool helps you to find the most relevant journal

- We provide round the clock customer support

- Convenient online submission

- Thorough peer review

- Inclusion in PubMed and all major indexing services

- Maximum visibility for your research

Submit your manuscript at www.biomedcentral.com/submit

) Biomed Central 